\title{
A ESCOLHA PELO PARTO DOMICILIAR: HISTÓRIA DE VIDA DE MULHERES QUE VIVENCIARAM ESTA EXPERIÊNCIA *A *B
}

\author{
The choice to give birth at home: Life Story of women who \\ experienced it. \\ La elección de parto domiciliario: Relato de vida de las mujeres \\ que pasaron por esta experiencia.
}

Renata Marien Knupp Medeiros ${ }^{1}$

Inês Maria Meneses dos Santos ${ }^{2}$

Leila Rangel da Silva ${ }^{3}$

\begin{abstract}
RESUMO
Estudo qualitativo cujo método foi a História de Vida. 0 objetivo foi analisar os fatores que influenciaram a escolha pelo parto domiciliar, assistido por enfermeira obstetra, a partir da história de vida das mulheres que vivenciaram esta experiência. Os sujeitos foram seis mulheres que pariram em domicílio em grandes centros urbanos. Foi realizada análise temática, emergindo uma categoria: A construção de uma escolha. Todas as entrevistadas fizeram referência às experiências de parto de suas mães, evidenciando a influência destas na construção de suas escolhas. Este grupo buscou informações; enfrentou tanto o modelo tecnocrático vigente como suas famílias; encontrou atendimento ao parto humanizado no ambiente acolhedor domiciliar. Concluise que o vínculo entre a enfermeira obstétrica e sua cliente, bem como o respeito por suas escolhas, expectativas e cultura proporcionaram segurança e confiabilidade às mulheres. A escolha informada deve ser tida como um direito. A satisfação com a experiência foi unânime.
\end{abstract}

Palavras-chave: Parto Domiciliar. Enfermagem Obstétrica. Comportamento de Escolha.

\begin{abstract}
Qualitative study. Followed the Life Story Method. The objective was to examine the factors that influenced the choice of home delivery assisted by obstetric nurses from the life story of women who experienced it. The subjects were six women that gave bir th at home in a large urban center. It was carried out with the use of thematic analysis, emerging the category: The construction of a choice. All women interviewed made reference to the experiences of childbirth of their mothers. This demonstrated the influence on the construction of their choices. The group obtained information; had to face both the current technocratic model and their families; and found humanized customer service in the delivery of the child in the warmth of home. The study concludes that that the link between obstetric nurse e and their client, as well as the respect of their choices, expectations and culture, providing self-confidence and security to these women. The informed choice should be guaranteed as a right. The satisfaction with this experience was unanimous.
\end{abstract}

Keywords: Childbirth at Home. Obstetrical Nursing. Choice Behavior.

\section{Resumen}

Estudio cualitativo, cuyo método fue Historias de vida El objetivo fue examinar los factores que influyeron en la elección del parto domiciliario asistido por una enfermera obstetra según la historia de vida de las mujeres que vivieron esta experiencia. Los sujetos del estudio fueron seis mujeres que tuvieron parto domiciliario en los grandes centros urbanos. Fue realizado un análisis temático, de donde emergió uma categoria: La construcción de una elección. Todas las entrevistadas hicieron referencia a las experiencias de parto de sus madres, lo que demuestra la influencia en la construcción de su elección. El grupo busco información; se enfrentaron tanto el actual modelo tecnócrata como a sus famílias; se encuentra la prestación de servicio humanizado en un el cálido ambiente del hogar. Se concluyó que el vínculo entre la enfermera obstetra y su cliente, así como el respeto de sus decisiones, la expectativas y la cultura proporcionaron seguridad y credibilidad a las mujeres. Así, la elección informada debe ser considerada como un derecho. La satisfacción con la experiencia fue unánime.

Palabras-claves: Parto Domiciliario. Enfermería Obstétrica. Conducta de Elección. 


\section{INTRODUCÃO}

0 presente estudo surgiu durante $02^{\circ}$ Encontro de Enfermagem Obstétrica e Neonatal do Estado do Rio de Janeiro, onde, em meio às exposições relacionadas com a atenção aos partos de baixo risco por enfermeiras obstétricas, uma das palestrantes explanou sobre sua experiência em assistir gestantes no ambiente domiciliar.

A partir deste relato, foi possível observar que, em meio aos altos índices de cirurgias cesarianas desnecessárias, e da crescente medicalização e intervenção deste processo natural e fisiológico que é o parto, tem aumentado, ainda que de forma tímida, a procura de gestantes pelo parto domiciliar no Estado do Rio de Janeiro.

No modelo de assistência atual, o parto no domicílio está relacionado às práticas culturais de comunidades isoladas com as parteiras, à dificuldade de acesso da usuária aos hospitais, seja pela ausência ou distância, e à falta de recursos econômicos da população. Mas é notório que o parto domiciliar planejado em grandes centros urbanos relaciona-se com uma questão de escolha pessoal da mulher.

A casa como lugar de nascimento tem voltado a fazer parte do cenário urbano contemporâneo. "Trata-se, contudo, não apenas de uma mudança de endereço, mas de uma mudança que envolve uma série de novos comportamentos, valores e sentimentos quanto à maneira de dar à luz, que vem sendo tecida no seio destas coletividades"1:6.

Grande parte das enfermeiras obstétricas que atuam nas grandes cidades vê o parto como um evento natural, que, se estiver bem acompanhado no pré-natal e livre de complicações, pode ocorrer fora do ambiente hospitalar.

A Lei do Exercício Profissional de Enfermagem $n^{0} 7.498 /$ 86 que, dentre outros, regulamenta o exercício da enfermeira obstétrica, garante que essas profissionais estão aptas a assistir ao parto normal de baixo risco e realizar os procedimentos necessários visando à segurança do binômio mãe-bebê. Estão capacitadas também para identificar distocias obstétricas que possam requerer cuidados médicos específicos².

De acordo com as recomendações da Organização Mundial de Saúde (OMS), o parto normal não deve ser medicalizado, e seu acompanhamento deve se dar com a utilização de um mínimo de intervenções realmente necessárias. Esta assistência deve estar direcionada a reduzir o uso excessivo da tecnologia sofisticada, quando procedimentos mais simples podem ser eficientes ${ }^{3}$.

Pode-se afirmar que o ambiente ideal para uma mulher dar à luz está relacionado com um local que the permita segurança no nível mais periférico, onde a assistência adequada for viável e segura. No caso de uma gestante de baixo risco, este local pode ser um centro de parto normal, uma maternidade de um hospital de maior porte, ou ainda o seu próprio domićlio. Entretanto, é importante que este ambiente possibilite cuidados centrados nas necessidades e segurança desta mulher, e esteja o mais perto possível de sua casa e de sua própria cultura ${ }^{4}$.

Considerando que cada mulher possui características próprias de experimentar a gestação a partir de sua história de vida, de valores pessoais e do meio sócio-cultural no qual está inserida, e, que ao optarem por um parto domiciliar planejado, contrariam "frontalmente a ideologia urbana vigente" ${ }^{5: 3}$, tornase relevante questionar: 0 que faz com que mulheres busquem ter seus filhos em casa, longe de todo o aparato tecnológico das instituições hospitalares?

Nesse sentido, delimita-se como objeto de estudo: a escolha da mulher pelo parto em ambiente domiciliar assistido por enfermeira obstétrica.

0 objetivo traçado foi: Analisar os fatores que influenciaram a escolha pelo parto domiciliar assistido por enfermeira obstétrica a partir da história de vida das mulheres que vivenciaram esta experiência.

A relevância deste estudo está na escassez de pesquisa sobre este tema. Após levantamento bibliográfico na BDTD utilizando como descritor "parto domiciliar", foram encontradas 22 referências. Após a retirada dos estudos com enfoque em epidemiologia, associados à morbimortalidade perinatal, restaram 9 que abordaram a temática como uma prática cultural de uma comunidade ou como uma escolha da mulher.

Espera-se com este estudo proporcionar aos profissionais da área obstétrica reflexões relacionadas à atenção oferecida à mulher e à real importância de vê-la inserida em uma história que lhe é particular, para a partir daí proporcionar um cuidado individualizado e qualificado, respeitando sempre suas expectativas, crenças e valores.

0 presente estudo visa difundir a temática, despertando 0 interesse pelo desenvolvimento de mais trabalhos relacionados com esta modalidade de assistência, bem como divulgar esta prática, permitindo assim que se torne uma escolha, tanto para as mulheres na hora de parir como para as enfermeiras obstétricas, como mais uma possibilidade de atuação .

\section{MÉTODO}

Trata-se de um estudo de natureza qualitativa, cujo método adotado foi a História de Vida, que permite obter informações na essência subjetiva da vida de uma pessoa, o que vai ao encontro do objeto de estudo. Entende-se que, se queremos saber a experiência e perspectiva de um indivíduo, não há melhor caminho do que obter estas informações através da própria voz da pessoa. Este método tem como característica respeitar a opinião do sujeito, não o vendo como objeto passivo, visto que é o entrevistado quem direciona o estudo a partir de sua visão de mundo, de como vivenciou os fatos e como interage com o presente ${ }^{6}$.

0 método História de Vida utiliza-se das trajetórias pessoais no âmbito das relações humanas. Busca conhecer as informações contidas na vida pessoal de um ou de vários informantes, fornecendo uma riqueza de detalhes sobre o tema. 
A História de Vida contempla a necessidade que o pesquisador tem em ouvir o cliente, conhecer o que ele pensa, sente e, principalmente, o que sabe e precisa'. "Os sujeitos têm liberdade para dissertar livremente sobre sua experiência pessoal em relação ao que está sendo indagado pelo entrevistador"\$:279.

0 cenário do estudo foi o domićílio das mulheres, sendo apenas uma entrevista realizada em local de trabalho. No momento da coleta dos depoimentos, uma depoente residia em outro estado, desta forma a entrevista foi realizada on line por um programa de áudio. Do universo de seis entrevistadas, apenas uma não pariu no Estado do Rio de Janeiro, tendo seu par to ocorrido em Porto Alegre, e todas foram assistidas por enfermeira obstétrica.

Em observância às diretrizes da Resolução 196/96 do Conselho Nacional de Saúde que regulamenta a pesquisa em seres humanos no Brasil, este estudo teve prévia autorização do Comitê de Ética em Pesquisa da Secretaria Municipal de Saúde do Rio de Janeiro (em 17/12/2007, protocolo nº. 214/ 07).

0 primeiro contato com as mulheres foi viabilizado por enfermeiras obstétricas que prestam assistência domiciliar no Rio de Janeiro e se deu através de uma visita a um dos encontros periódicos realizados por esta equipe, onde se reúnem: profissionais, clientes, companheiros e seus respectivos filhos. Dentre as mulheres que tiveram pelo menos um parto domiciliar planejado em grande centro urbano, foram entrevistadas aquelas que demonstraram interesse em participar do estudo, após serem esclarecidas sobre sua temática e objetivos.

A segunda abordagem foi realizada através de correio eletrônico (e-mail) e/ou contato telefônico. Neste momento as entrevistas foram agendadas de acordo com a disponibilidade das depoentes.

0 roteiro para obtenção dos dados foi composto inicialmente por questões que envolveram dados de identificação da mulher e sua história reprodutiva. A técnica adotada para a coleta dos depoimentos foi a entrevista aberta e prolongada, e o direcionamento dos relatos foi realizado com uma única pergunta: "Fale sobre sua vida que tenha relação com sua escolha pelo parto domiciliar."

Os relatos, que duraram em média 60 minutos, foram gravados em fitas magnéticas (K7) e transcritos na íntegra imediatamente após serem realizados, a fim de garantir maior fidedignidade das respostas e evitar a perda de qualquer informação relevante. No intuito de garantir o sigilo e anonimato, foram utilizadas pedras preciosas como codinomes para as depoentes, e os nomes das demais pessoas mencionadas nos relatos foram trocados por suas iniciais. Após a realização das seis entrevistas, atingiu-se o ponto de saturaçã ${ }^{7-9}$.

0 grupo estudado foi composto por seis mulheres com idades entre 29 e 40 anos, sendo uma delas residente do Estado da Paraíba, uma do município de São Gonçalo - RJ, e as demais (4) do município do Rio de Janeiro, em bairros da Zona Sul e Oeste.
Dentre as depoentes, $84 \%$ (5) delas são casadas, $84 \%$ (5) possuem $3^{\circ}$ grau completo (veterinária, juíza do trabalho, comércio exterior, advogada e médica), e uma, $2^{\circ}$ grau incompleto (microempresária).

Em relação à história obstétrica, 84\% (5) foram primíparas, e uma multípara, sendo esta submetida a duas cesarianas. As mulheres entrevistadas vivenciaram os partos domiciliares entre os anos de 2004 e 2007.

\section{RESULTADOS E DISCUSSÃO}

A análise de uma história de vida tem por objetivo explicitar as informações e significados pertinentes nela contidos. A maioria dessas informações e significados não aparece na primeira leitura; sem dúvida, a experiência demonstra que vão surgindo uma atrás das outras no transcurso das leituras sucessivas. Cada leitura revela novos conteúdos semânticos? ${ }^{7}$.

Foi empregado a análise temática, que "consiste em reportar em cada relato de vida as passagens concernentes a tal ou qual tema, com o objetivo de comparar depois os conteúdos dessas passagens de um relato a outro"7:99. Porém, foi respeitada a individualidade e a especificidade de cada depoimento. 0 discurso foi decomposto, reagrupado e interpretado ${ }^{8-9}$, emergindo uma categoria analítica que contemplou os fatores que influenciaram a escolha das mulheres pelo parto domiciliar a partir da história de vida, que foi denominada: A Construção de uma Escolha.

\section{A Construção de uma Escolha}

Foi notório que escolhas e decisões quanto ao tipo de parto foram decorrentes de um processo que envolveu múltiplos fatores. Alguns deles foram facilmente identificados diante de um discurso, outros, porém, podiam estar relacionados à história de vida das mulheres de forma tão intrínseca que muitas vezes não foram relatados como influenciadores de determinada ação.

0 parto é visto como um processo psicossomático, no qual as escolhas e o comportamento da gestante ou parturiente estão relacionados não só com a própria evolução da gestação ou do trabalho de parto, mas também com o "nível de informação da mulher, sua história pessoal, contexto sócio-econômico, personalidade e simbolismo"10.

A partir da análise dos depoimentos, foi possível perceber que todas as entrevistadas fizeram referências a alguma história de parto que já tinham ouvido ou vivenciado junto a um familiar ou amigo próximo, ficando evidente a influência que estas histórias exerceram na formação da opinião destas mulheres ao longo suas vidas.

Segundo o médico obstetra francês Michel Odent, "cada gestante chega trazendo uma história cultural, familiar e pessoal única que terá uma forte influência no curso do seu trabalho de parto" 11:23, como pode ser observado na fala a seguir:

Eu sempre tive muito desejo de ter um parto normal, desde pequena mesmo. Eu tive um irmão temporão quando eu tinha treze anos, então desde essa época 
eu vivi muito essas coisas de gravidez e parto com eles. Acho que isso me influenciou muito mesmo de querer um parto normal. (Rubi)

Mulheres que pariram em casa "relatam histórias contundentes que dão ao parto um significado positivo e de naturalidade" "5:36. Memórias de parto com cunho positivo foram mencionadas na maioria dos depoimentos, o que assegurou a estas mulheres confiança no processo natural e fisiológico do nascimento, justificando em muitas delas o desejo pelo parto vaginal.

Parto normal, eu acho que é meu mesmo. Eu queria porque eu pensava assim, que ser mãe tinha que passar por isso, eu acho que não era fazer cesárea. Eu penso que uma mulher pra se realizar precisa passar... Eu precisava passar por essa experiência pra eu me realizar, eu queria de todo modo fazer um parto normal. (Safira)

Desde que eu era adolescente, pré-adolescente, quando o papo era parto, eu falava que queria ter meu parto na água, e me imaginava numa piscininha. (Pérola)

Minha mãe teve dois filhos de partos normais hospitalares, os dois filhos dela. Ela sempre falou de uma forma positiva a respeito do parto normal, então eu não me via tendo filhos de outra forma. (Ametista)

Dentre as temáticas abordadas, há de se ressaltar a menção que todas as entrevistadas fizeram às experiências de suas mães quanto ao processo parturitivo. As histórias de parto que marcaram a história pessoal destas mulheres constituíram "0 cenário básico onde a idéia de parto se formou"5:36.

Odent afirma ainda que em algumas famílias existe, virtualmente, a tradição de partos mais fáceis. A mulher leva para o parto toda a experiência alcançada durante sua vida. Portanto torna-se relevante conhecer o que cada mulher sabe sobre o seu próprio parto, visto que freqüentemente existe uma relação entre como ela nasceu e como ela irá trazer sua própria criança ao mundo. Trabalhos de parto difíceis geralmente são esperados quando existe uma história materna de parto difícil; por outro lado, se os partos maternos transcorreram em casa, faz-se pensar em um par to fácil ${ }^{11}$.

Minha família é da roça, então as minhas avós, bisavós, todas tiveram filhos em casa. Minha avó, mãe da minha mãe, teve catorze filhos dentro de casa com parteira da região, todos nasceram normais sem nenhum problema. Minha mãe é super a favor do parto normal, teve quatro filhos de parto normal, então eu sempre tive essa visão. Minha avó por parte de pai também chegou a ter filho em casa, porque é da roça, interior, então talvez essa coisa de a familia ter tido filhos dessa forma, pode ser que de alguma maneira isso tenha me influenciado. (Cristal)

Contudo, pôde-se observar que as entrevistadas cujas mães não tiveram boas experiências perinatais, como contato mãebebê prejudicado pelo pós-parto cesáreo e nascimento a fórceps, não reprimiram o desejo de vivenciarem uma experiência de parto natural. A partir destas histórias de cunho negativo da experiência materna foi possível perceber a necessidade destas mulheres de proporcionar para seus filhos um nascimento seguro, em que pudessem estar em contato e amamentar seus bebês logo após o nascimento, tentando suprir de alguma forma o que lhes faltou.

Eu tinha uma angústia muito grande com essa coisa da separação, do hospital, do neném nascer e eles levarem. (Rubi)

Este grupo de mulheres procurou conhecer cada vez mais sobre todo o processo de gestação e parto, a fim de se sentirem preparadas para escolher o tipo de assistência que realmente atenderia os seus anseios. É interessante salientar que todas as entrevistadas buscaram incessantemente por informaç̧ões.

Eu não tinha muita informação na verdade, e nem sabia a diferença entre a enfermeira obstetra e a doula, eu não tinha muita noção. (Rubi)

Eu achava que aquelas intervenções eram realmente necessárias. Episiotomia, aquela manobra... Eu só fui entender esses nomes depois que eu estava grávida e comecei a ler. (Ametista)

0 fato de a maioria das entrevistadas possuir curso superior e um nível socioeconômico que favoreceu acesso à internet, TV por assinatura, vídeos, livros e artigos que abordassem a temática permitiu que elas conhecessem mais sobre os modelos de assistência ao parto, favorecendo assim uma escolha informada.

Realmente você começa a pensar como vai ser no hospital, como vai ser em casa, mais antes de pesquisar eu não pensava em ter em casa assim não. Eu fui atrás do parto domiciliar porque fui me esclarecendo, pesquisando coisas. Meu marido mesmo gosta de entrar na internet e pesquisar, e aí a gente começa a enxergar ou outro lado, que não mostram quase, a mídia não mostra. (Safira)

A opção das entrevistadas pelo parto domiciliar em grandes centros urbanos foi notadamente relacionada com o acesso a informações que em geral não são acessíveis à maioria das 
mulheres. Este elemento pareceu ter grande influência na opção da mulher e sua família pelo par to domiciliar planejado ${ }^{5}$.

0 direito à escolha informada por parte da mulher sobre a forma de dar à luz constitui, na área da saúde, um direito humano e um direito reprodutivo, apontado em vários instrumentos legais nacionais e internacionais ${ }^{12}$.

Na internet eu li "amigas do parto" [website], e ali foi o X da questão. Quando eu peguei e comecei a ler o que era cada tipo de parto, que eu podia ter um parto humanizado, tudo o que a OMS prega que não deve maltratar a mulher na maternidade, que a mulher pode escolher sua própria posição... Aí eu comecei a ler, ler, ler, achei aquilo tudo muito claro, imprimi tudo, um bolo assim e fiquei lendo... Então pensei: Gente mais é isso que eu preciso! Não dá pra ser diferente, eu quero ter uma coisa assim! (Cristal)

A necessidade de permitir com que as mulheres escolham sua forma de parir foi mencionada na II Conferência Internacional de Promoção da Saúde (1988) e deu origem à Declaração de Adelaide. Este documento propôs a criação de políticas públicas voltadas para a prática de parto baseada nas preferências e necessidades das mulheres, evidenciando assim a importância de deixar com que elas protagonizem o seu próprio parto ${ }^{13}$.

Ser protagonista do seu parto envolveu, entre outras coisas, a busca pela informação a respeito dos direitos sobre os cuidados que se pode receber e exigi-los, além de assumir uma postura ativa frente à equipe de atendimento 1 .

\section{Eu não sei até que ponto as pessoas se alienam de tentar saber, porque é difícil a decisão, é importante ler, não ficar alienado das coisas. Hoje eu falo com minhas amigas, tu teve episiotomia? E elas não sabem dizer, ninguém sabe nem os nomes das coisas só sabem se levou anestesia. (Esmeralda)}

Cabe ressaltar que além de essas mulheres terem buscado de forma ativa por esclarecimentos sobre o processo de gestar e parir, a construção de novos conhecimentos juntamente com a enfermeira obstétrica durante as consultas de pré-natal aconteceu durante todo o período gestacional.

0 pré-natal é completamente diferente. Ela [enfermeira obstetra] explicava todas as etapas, como estava acontecendo, o que estava acontecendo com o meu corpo, o que poderia indicar pra ela se o parto ia correr tudo bem. Então foi assim, tudo bem explicado, então eu fui me preparando para que aquilo acontecesse tudo certinho em casa, eu já estava sabendo tudo o que ia acontecer comigo. (Safira)
A participação no planejamento do parto, 0 acolhimento recebido e a abertura para que a mulher pudesse colocar suas histórias, sentimentos, dúvidas e medos favoreceram a criação de um vínculo importante entre as usuárias e as prestadoras do serviço, garantindo uma relação de confiança na profissional.

A preparação foi muito grande do pré-natal até eu chegar no parto domiciliar, não é assim 'eu quero e vai lá e faz', tem que ter uma preparação muito grande pra você entrar no trabalho de parto tranqüila e passar por aquilo numa boa. (Cristal)

Ela [enfermeira obstetra] foi fundamental neste processo, não tenho dúvida disso, éuma coisa muito importante esse vínculo, e acreditar nesse profissional que está com você na hora que seu filho nasce. Vai muito além da troca de dinheiro, é um encontro de alma, é uma amizade muito bonita, profunda. (Pérola)

0 atendimento pré-natal diferenciado, proporcionado pela enfermeira obstétrica, foi valorizado na fala de todas as depoentes. Das seis entrevistadas, cinco delas iniciaram o acompanhamento pré-natal com médico obstetra, porém, devido à insatisfação com a conduta intervencionista e autoritária recebida, elas se sentiram motivadas a buscarem um atendimento mais humanizado.

Como ela [médica obstetra] estava vendo que eu queria ter parto normal, me informou que dava preferência para gestantes que queriam cesárea, porque ela tinha filho pequeno, tinha os problemas particulares dela, e não poderia me atender a qualquer momento de madrugada. Ai eu pensei, como vou agora com seis meses de gravidez ter vínculo? Porque eu tinha vínculo com ela, talvez ela não tivesse comigo, mais eu tinha. (...) Ela falou assim: Quanto ao pai assistir você não precisa se preocupar, porque nos meus partos, pai não entra! (Ametista)

De acordo com a antropóloga americana Davis-Floyd, esta forma de assistência representada pelos relatos está pautada no modelo tecnocrático, que acredita na separação entre mente e corpo, sendo este último visto como uma máquina. Esta forma de atuação profissional supervaloriza a ciência e a tecnologia, e vê o cliente como um objeto passivo de intervenções agressivas, visando um resultado rápido ${ }^{14}$.

As consultas [médicas] eram muito curtas, era sempre medir barriga, pedir ultra, ver pressão... 0 tempo foi passando e eu cheguei a seis meses de gravidez, quando virei pra ela e falei: Vamos conversar sobre o parto? Como é que vai ser? (Ametista) 
São indiscutíveis os benefícios que os avanços científicos e tecnológicos proporcionaram à obstetrícia. Exames específicos e aparelhos sofisticados permitiram um melhor controle dos riscos materno-fetais, e a cirurgia cesariana surgiu como um procedimento que em algumas situações proporciona uma maior segurança à vida, tanto da mulher como do bebê.

Observa-se, porém, que com o advento da tecnologia, muitos procedimentos passaram a ser utilizados sem justificativas obstétricas adequadas, e os resultados negativos do tecnicismo reflete em: epidemia de cesarianas, alta mortalidade materna e alta morbidade perinatal, insatisfação das usuárias e custos estratosféricos ${ }^{14}$.

A minha prioridade é fazer parto normal, mas é assim: você chega lá, se tiver com dor a gente já faz uma anestesia, aína hora do parto se tiver qualquer coisa a gente faz uma cesariana sem problema. (Esmeralda)

0 descontentamento com este tipo de assistência e a sensação de que perderiam muitas coisas ao se entregarem sem questionamentos às rotinas rígidas da obstetrícia tradicional impulsionaram estas mulheres a buscarem um modelo de assistência que respeitasse o processo de gestar e parir e lhes pudesse proporcionar um nascimento que ocorresse de forma fisiológica e natural.

[...] a segunda questão que me levou muito a isso é que eu descobrique não precisava ir para o hospital, porque eu achava até que era proibido, na minha cabeça eu achava que nem podia, que você tinha que ir, que era obrigatório ir para o hospital. (...) Eu realmente não gosto de hospital. (Rubi)

0 estranho pra mim não é ter filho em casa, o estranho pra mim é ir pro hospital. Ehospital tem isso, essa coisa louca de que você quando entra no hospital perde essa autonomia, essa identidade. Você põe aquela camisolinha ali... É um negócio tão cruel muitas vezes, que você não quer, o quanto você puder evitar isso melhor. Aquela luz toda na sua cara, com aquelas pessoas nada a ver, não tem por quê, a princípio, não teria por quê. (Pérola)

Cabe ressaltar que a maioria das mulheres que optou pelo parto domiciliar planejado teve como enfrentamento não só 0 modelo medicalizado, intervencionista e institucionalizado, mas também a sua própria rede familiar e de amigos, que tinham este modelo como o mais adequado e seguro.

[...] comecei a contar pra minha família que eu pretendia ter o bebê em casa, e aí começou uma preocupação muito grande. Todo mundo muito preocupado que isso era um risco, e que eu estaria sendo irresponsável, então isso foi pra mim um choque. (...) Eu falo no assunto, mais muitas pessoas não querem nem me ouvir, não foram me visitar em casa, outras pessoas nunca me perguntaram sobre o parto, eu fui vista como louca, como irresponsável, mas ninguém tá dentro de mim, ninguém viveu 0 que eu vivi, ninguém foi atrás das coisas que eu fui. (Esmeralda)

Diante deste modelo hegemônico vigente, enraizado não só nas condutas dos profissionais, mas também na população, o modelo humanista vem contrapor os excessos da assistência tecnocrática. 0 Programa de Humanização do Pré-natal e Nascimento, instituído pelo Ministério da Saúde (MS) em 2000, tem como princípio o direito da gestante a um atendimento digno e de qualidade, realizado de forma humanizada e segura no decorrer da gestação, parto e puerpério ${ }^{16}$.

Tendo em vista que as enfermeiras obstétricas vêm se preocupando e se empenhando cada vez mais na melhoria da assistência, e que elas têm sido apontadas como importantes mediadoras não só no trabalho de parto e nascimento, como também na humanização do ciclo gravídico-puerpera ${ }^{17}$, desde 0 ano 2000 sua atuação vem sendo estimulada e apoiada pelo MS, visando à melhoria da assistência obstétrica no Brasil.

Contudo, é importante ressaltar que sem a devolução do protagonismo para a mulher não existe humanização do nascimento. Enquanto elas não puderem escolher livremente a posição para parir, sua companhia, o local, sua roupa, suas tradições e suas inúmeras vontades, apenas estará sendo reproduzida uma história de abusos e interferências desnecessárias, que não procede num mundo que se propõe democrático e igualitário ${ }^{14}$.

Neste sentido, justifica-se a escolha das mulheres pelo parto domiciliar, cabendo destacar que o par to que evolui de forma fisiológica e natural tem o domicílio da parturiente como cenário ideal, uma vez que este ambiente possibilita acolhimento, privacidade, confor to e liberdade para escolhas.

[...] você quer estarna sua casa, com teus familiares, pra mim é fundamental também ter o filho na minha casa, no meu espaço, no espaço onde eu estou familiarizada, com meu marido. Foi só eu He E... eu não queria ninguém, é uma experiência muito intima, sabe?(Pérola)

[...] também teve isso de poder estar em casa, um lugar acolhedor, um lugar em que eu me sinto bem. É minha casa, tem toda uma história, não é a minha casa, é a nossa casa, que eu montei junto com o M, então é muito legal isso, eu me senti com muita liberdade, muito a vontade. (Rubi) 
Estas mulheres demonstraram grande satisfação por poderem estar num ambiente acolhedor, acompanhadas de pessoas especiais escolhidas por elas, e deterem de toda a autonomia e liberdade para optarem quanto ao que fazer, 0 que comer, onde ficar, neste momento tão especial e marcante de suas vidas.

Fez uma diferença enorme na minha vida, acho que eu não seria a mesma se eu não passasse por isso, é realmente uma realização! Foi tudo o que eu queria! (Safira)

Eu acho que todas as mulheres deveriam se permitir parir assim, a gente foi feita pra isso, a gente tem capacidade pra isso. Eu defendo o parto domiciliar porque eu acho que realmente é o melhor pra gente. (Esmeralda)

Quando eu engravidar de novo, é em casa, não tem outro jeito, não tem como ser diferente, é muito bom! (Ametista)

0 desejo por repetir a experiência do parto em casa em uma próxima gestação foi citado por muitas destas mulheres, comprovando, assim, a experiência positiva para a totalidade delas que tiveram seus domićlios como um ambiente facilitador do parto natural.

É necessário refletir no que a assistência ao parto tem desagradado às mulheres, o que se tem feito no sentido de melhorar este modelo institucionalizado, e o que faz com que mulheres evitem este tipo de atendimento e busquem vivenciar o parto desejado.

O Ministério da Saúde vem implementado ações no sentido de melhorar e incentivar o parto normal no Brasil, como a abertura de Casas de Parto que permitem a mulher parir assistidas por enfermeiras obstétricas num ambiente semelhante ao domicílio, local este que, além do acompanhante, permite privacidade, liberdade, confor to e afetividade.

A Agência Nacional de Vigilância Sanitária (ANVISA) também tem atuado no sentido de tornar o parto mais humanizado. Recentemente reuniu uma série de normas a serem cobradas dos hospitais públicos e particulares e clínicas para mudanças na rotina da maternidade; dentre elas cabe ressaltar a garantia das mulheres em escolher a posição do parto: de cócoras, na água ou deitada.

Preocupada com os altos índices de parto cesáreo na saúde suplementar, a Agência Nacional de Saúde Suplementar (ANS) também lançou uma campanha em favor do parto normal, visando à redução das cesarianas desnecessárias. Outra medida de destaque foi a cobertura dos partos assistidos por enfermeira obstétrica, e da presença de um acompanhante durante toda a estada da mulher no hospital.

Porém, é preciso destacar que ainda há muito para se fazer a fim de garantir um parto seguro, digno e respeitoso para todas as mulheres como preconiza a OMS. 0 direito à escolha informada deve ser respeitado pelos profissionais que prestam atendimento a esta clientela. Dar-lhe acesso às informações baseadas em evidências científicas permite que esta mulher tenha instrumentos necessários para escolher o tipo de parto que mais Ihe agrada.

\section{CONSIDERAÇÕES FINAIS}

0 conhecimento da história de vida destas mulheres tornou possível afirmar que a escolha por um parto fora do modelo institucionalizado esteve relacionada com suas experiências vivenciadas desde o seu próprio nascimento até o momento do parto de seus filhos.

A partir dos depoimentos, ficou claro que cada mulher trás consigo uma história única, que foi valorizada de forma individual. A criação do vínculo entre a enfermeira obstétrica e sua cliente bem como o respeito pelas escolhas, expectativas e cultura permitiram uma maior segurança e confiabilidade por parte destas mulheres.

Este estudo foi composto por uma maioria de mulheres com nível universitário e uma condição socioeconômica privilegiada que permitiram acesso à informação sobre todo 0 processo de parto e nascimento e os tipos de assistência nestes eventos, o que as ajudou na tomada de decisão quanto ao tipo de parto que gostariam.

Infelizmente a maioria da população de gestantes no Brasil não possui acesso a estes conhecimentos, seja por possuírem uma condição socioeconômica inferior e baixo nível de escolaridade que impedem o acesso, seja pela negligência dos profissionais de saúde que não consideram a escolha informada um direito da mulher.

Cabe ressaltar que as consultas de pré-natal foram um momento adequado para que as enfermeiras obstétricas compartilhassem com as mulheres conhecimentos a respeito da fisiologia, tipos e posições de parto, e uso de tecnologias não invasivas, permitindo, assim, a participação da mulher na elaboração do seu plano de parto.

De acordo com os relatos, as depoentes demonstraram grande satisfação pela vivência do parto domiciliar, sendo unânime neste grupo o desejo de repetir a experiência, considerada por elas uma oportunidade marcante de autoconhecimento e superação.

A formulação de políticas públicas e o incentivo de órgãos governamentais no sentido de expandir este serviço poderiam possibilitar que esta experiência tão gratificante vivenciada por estas mulheres se tornasse acessível a toda população. 


\section{Referências}

1. Souza HR. A arte de nascer em casa: um olhar antropológico sobre a ética, a estética e a sociabilidade no parto domiciliar contemporâneo. [dissertação de mestrado]. Florianópolis (SC): Programa de Pósgraduação em Antropologia Social / UFSC; 2005.

2. Lei $n^{0} 7.498$ de 25 de junho de 1986. Dispõe sobre a regulamentação do exercício da enfermagem, e dá outras providências. Diário Oficial da República Federativa do Brasil, Brasília (DF), 26 jun 1986: Seção $1: 1$.

3. Ministério da Saúde (BR). Pré-natal e puerpério: atenção qualificada

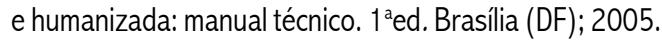

4. Organização Mundial de Saúde (OMS). Maternidade segura: assistência ao parto normal: um guia prático. Genebra (CH); 1996.

5. Lessa HF. Parto em casa: vivências de mulheres. [dissertação de mestrado]. Rio de Janeiro (RJ): Universidade do Estado do Rio de Janeiro; 2003.

6. Glat R. Somos iguais a você: depoimento de mulheres com deficiência mental. Rio de Janeiro (RJ): Agir; 1989.

7. Bertaux D. Los relatos de vida. Barcelona (ES): Bellaterra; 2005.

8. Santos IMM. 0 olhar da mãe sobre o desenvolvimento do seu filho no contexto da sua história de vida. [dissertação de mestrado]. Rio de Janeiro (RJ): Escola de Enfermagem Anna Nery/ UFRJ; 1998.
9. Dias IMV, Santos RS. Método história de vida e sua aplicabilidade no campo da enfermagem. Esc Anna Nery Rev Enferm 2005 ago; 9 (2): 278-86.

10. Davim RMB, Menezes RMP. Assistência ao parto normal no domicílio. Rev Latino-am Enfermagem 2001 nov; 9(6): 62-8.

11. Odent M. 0 renascimento do parto. Tradução de Roland B. Calheiros. Florianópolis (SC): Saint Germain; 2002.

12. Diniz SG, Duarte AC. Parto normal ou cesárea? 0 que toda mulher deve saber e todo homem também. Sâo Paulo (SP): Ed UNESP; 2004.

13. Declaração de Adelaide. Segunda Conferência Internacional sobre promoção da saúde. [on-line] Austrália; 1988 abr; [citado 11 jun 2008]. Disponível em: http://www.opas.org.br/promocao/uploadArq/ Adelaide.pdf.

14. Jones R. Memórias de um homem de vidro: reminiscências de um obstetra humanista. Por to Alegre (RS): Idéias a Granel; 2004.

15. Davis Floyd R. Del medico al sanador. Buenos Aires (AR): Ed Creavida, 2004.

16. Ministério da Saúde (BR). Humanização do parto: humanização no pré-natal e nascimento. Brasília (DF); 2002.

17. Crizóstomo CD, Nery IS, Luz MHB. A vivência de mulheres no parto domiciliar e hospitalar. Esc Anna Nery Rev Enferm 2007 mar; 11 (1): 98-104.

\section{Notas}

*a Trata-se de um recorte do trabalho de conclusão de curso de graduação de Renata Marien Knupp Medeiros, apresentado à Escola de Enfermagem Alfredo Pinto, da Universidade Federal do Estado do Rio de Janeiro (UNIRIO).

*b Agradecimentos:

Agradeço a todas informantes que participaram da pesquisa pela solicitude com que me receberam, e por compartilharem suas histórias de vida. Agradeço de forma especial às enfermeiras obstétricas Heloísa Lessa e Maysa Ludovice pela confiabilidade ao facilitarem o contato com suas clientes. A realização deste estudo não seria possível sem a colaboração de vocês. 